\title{
Problemas de la implantación agraria romana y la organización del territorio en la península ibérica en el Alto Imperio
}

\author{
Manuel Villanueva Acuña *
}

En este trabajo pretendemos abordar el estudio de la villa como base para un análisis del espacio rural.

Excluimos de nuestro estudio otras formas posibles de asentamiento sobre las que la arqueología está muy lejos de iluminarnos con precisión. Sin embargo no dejaremos de lado el análisis de ciertas transformaciones conocidas en ciertos lugares y que muestran la influencia de la romanización en el nacimiento de villae sucediendo a viejos asentamientos indigeneas ${ }^{1}$.

\footnotetext{
* Departamento de Historia 1. Area de Historia Antigua. Fac. de Geografía e Historia. Universidad de Santiago de Compostela.

Merce PItA, R., "Mosaicos romanos tardíos en las comarcas del Segre y Cinca", BSSA XXXIV-XXXV, 1969, págs. 31-64, trata en profundidad el problema de la evolución del poblamiento rural en la comarca; GaRcia Merino, C., cuyos estudios sobre la ciudad y el territorio de Uxama son muy interesantes: "La ciudad romana de Uxama, II", BSAA XXXVII, 1971, págs. 85-119; "Tres yacimientos de época romana inéditos en la provincia de Soria", BSAA XXXIII, 1967, págs. 167-209; "La evolución del poblamiento de Gormaz (Soria)", BSAA XXXIX, 1973. "Un sepulcro romano turriforme en la Meseta Norte", BSAA XLIII, 1977, págs. 41-54.; "Desarrollo urbano y promoción politica de Uxama Argaela", BSAA LIII, 1987, págs. 73-114. MARTin TOBIAS, R., "Poblamiento layetano en el Maresma sintesis de un estudio general», VII Congreso Arqueológico Nacional, 1960, págs. 240-250, para la región del Maresme; SERRA RAFOLS, J. DE C., para la costa catalana: "Estratos ibéricos debajo de villas romanas de la Costa catalana", VII Congreso Arqueológico Nacional, 1960, págs. 255-260. En el caso galaico también FerReIRA DE ALMEIDA, C. A., ARIAS Vilas, F., y CAVADA Nieto, M., "Galicia Bajorromana", Gallaecia, 3-4, 1977-8, pág. 98, que aducen la posibilidad de que la aristocracia indígena que edificó villae en el llano conservase sus viviendas en los castros como parte dependiente de las anteriores o bien, que en época bajoimperial sirviesen los castros como alojamiento de campesinos o colonos. Rodriguez Colmenero, A., Galicia Meridional Romana. Deusto 1977, pág. 172 ss.
} 


\section{LAS VILLAE DE HISPANIA}

El primer problema que no presenta para la península lbérica es la descripción de las propias villae: tanto a) su definición, según los textos de los agrónomos latinos, como b) la configuración que en la península ibérica éstas toman segun la arqueología.

a) Sobre la definición y el concepto de villa hay mucho avanzado desde los estudios que a esta materia dedicaron desde el siglo pasado diversos investigadores ${ }^{2}$.

La conclusión más importante que debemos asumir antes de abordar una revisión de las fuentes latinas es la ausencia de una especialización del significado del término villa para los latinos. El término parece indicar edificación en el campo, por oposición a la de la ciudad: aedificium; e incluye tanto edificaciones rústicas destinadas a soportar la actividad agricola como edificaciones que buscan ante todo servir de lugar de esparcimiento y de recreo (otium) para sus propietarios, pasando por una amplia gama de situaciones intermedias.

b) La configuración que las villae toman en la Península depende para su conocimiento de los ejemplares excavados. Los establecimientos conocidos y que han sido objeto de investigación son muchos, pero ninguno de ellos fue excavado en toda su extensión, lo que nos sitúa ante problemas complejos.

2 La literatura que recoge definiciones de villae y sus características es extensa. Destacaremos a G. Lafaye - voz villa - en DaREmBERG-Saglio, Dictionnare des Antiquités; también en PERcival, The Roman Villa. Londres 1976, pág. 13-15, encontramos unas referencias a esa cuestión, $y$, en los estudios dedicados a las villae en la Península lbérica: los de GORGES, J., Les villas hispano-romaines. Inventaire et problematique archeologiques. Paris 1979, y FERnANDEz CASTRO, C., no falta un estudio de las referencias de los autores latinos y su concepción de las villae, tanto en su vertiente arquitectónica como los emplazamientos ideales y el tipo de explotación agraria de la que el edificio es el núcleo, siendo especialmente completo el realizado por la segunda en: Villas Romanas en España. Madrid 1982, cap. I, pág. 23 ss. Un útil y actualizado tratamiento de la cuestión en PEREZ LOSADA, F., "Sobre o concepto de villa no mundo romano". Cuadernos de Arqueología II, 4, 1987, págs. 79-110. También Martino, F. de, Historia económica de la Roma antigua, I, págs. 129-30, nos da útiles referencias sobre su evolución y su actividad económica. Sobre este último aspecto: WHITE, K. D., Roman Farming. Londres 1970; KOLENDO, J., L'agricoltura dell'ttalia romana. Roma 1980. 
En primer término señalemos que pocas villae han sido objeto de una excavación metódica ${ }^{3}$, y que ninguna de ellas fue completada hasta descubrir enteramente su recinto.

Como consecuencia de lo anterior, problemas como la tipología de muchas de las villae están resueltos de manera provisional y con un cierto margen de inseguridad. No es, sin embargo, la cuestión de la tipología de las construcciones el asunto que atrae nuestra atención, y para reflejar el estado actual de la cuestión, creemos que continúan siendo válidad las conclusiones de J. Gorges, y, sobre todo, las del mucho mejor elaborado estudio de M. C. Fernández Castro ${ }^{4}$.

De esta manera, con las reservas que los insatisfactorios resultados de la exploración arqueológica imponen a la hora de establecer conclusiones definitivas, parece evidente la filiación existente en sus plantas de las villae hispanas respecto del tipo de casa mediterránea que representa la villa romana o italiana, organizada en torno a un espacio abierto -el peristilo - frente al modelo nórdico, representado por las villae de galería con torres angulares típicas de las provincias del Norte de la Galia, de Germania o Britania, de las cuales los ejemplos conocidos con certeza en Hispania son muy escasos.

Considerando los objetivos de nuestro estudio, el hecho de que las excavaciones realizadas tengan un carácter parcial resulta un obstáculo serio que debemos valorar en toda su dimensión. Lo que conocemos de las villae peninsulares son, sobre todo, mosaicos, hipocaustos y partes relativamente limitadas de sus recintos, cuyo destino no siempre es precisado; pocas son las plantas que se pueden reconstruir con verosimilitud, y hay un vacio muy grande en el conocimiento de una completa estructura constructiva con todas sus dependencias. Ninguna villa en Hispania fue descubierta por completo, con todos sus componentes, como ya anteriormente señalamos.

A pesar de todo, esos obstáculos creemos que no son insuperables para llevar a término nuestro estudio. Nuestro objetivo se orienta hacia la relación existente entre las villae, como formas de habitat y de explotación económica, y la organización del territorio en las comunidades de la

${ }^{3}$ Destaquemos los casos de Liédena en Navarra, Almenara de Adaja en Segovia, La Cocosa, Badajoz, y Torre de Palma, cerca de Monforte, Portugal. Citaremos especialmente las monografías que se tratan de esos establecimientos excavados.

${ }^{4}$ Esta autora aborda de manera mas sistemática que $\mathrm{J}$. Gorges la clasificación de las plantas de la villae peninsulares: Villas romanas en España: cap. III, p. 60 ss., y cap. IV, p. 150 ss. 
península. Para esto podemos utilizar, aunque con cierto margen de desconfianza las noticias que en abundante cantidad, si bien en menos calidad, dieron a conocer la existencia de establecimientos desde hace bastante tiempo. Esta información fue recopilada por J. Gorges y M. C. Fernández Castro hasta 1977 aproximadamente, aunque desde entonces el volumen de la información acumulada en los últimos años se ha incrementado bastante, circunstancia de la que nos hemos hecho eco, dentro de los modestos objetivos de nuestro trabajo incorporando los resultados de intensas prospecciones que en diversas áreas de la península dieron lugar al descubrimiento de nuevos establecimientos. Estas nuevas actividades que culminaron en la excavación de nuevas estaciones alteran sustancialmente el panorama que conocíamos en algunas áreas de la península, pero no implican, sin embargo, una radical transformación de la distribución de yacimientos o villae con respecto a las conocidas anteriormente, en el cojunto de las regiones peninsulares; más bien, los nuevos descubrimientos confirman la situación que los datos anteriores y las condiciones del territorio podían prever. Así sucede con los resultados de las prospecciones llevadas a cabo en el territorio de Emerita Augusta ${ }^{5}$, en el Valle del Guadalquivir ${ }^{6}$, y en cualquiera de las áreas donde la exploración organizada y el estudio sistemático de los emplazamientos de villae sustituyen a la simple recopilación de noticias dispersas originadas por hallazgos casuales.

\section{DISTRIBUCIÓN GEOGRÁFICA}

Consideramos que podemos sostener con fundamento la hipótesis de que las villae aparecen con más frecuencia en las áreas que reúnen las siguientes condiciones:

1. Riqueza del territorio, que se manifiesta en la coincidencia de factores favorables como: fertilidad, situación favorable, clima benigno $y$

Asi estudios como los de Cerrillo Martin de Caceres, E., y otros, que serán citados más adelante.

${ }^{6}$ Cfr. los trabajos de PONSICH, M., precedidos del coloquio dirigido por R. Etienne: "Structures agraires antiques dans la región de Seville: Essai de problématique" MCV, VIII, 1972 , que son la base de la que parte el estudio de la implantación rural romana en el Valle de Guadalquivir, como continuación de los trabajos de G. Bonsor y R. Thouvenot. 
posibilidad de un buen abastecimiento de agua, en las villae agrarias; minas y pesca en villae mineras o marineras.

2. Proximidad de vías de comunicación, como el mar, ríos navegables o calzadas.

3. Existencia de ciudades, en la órbita de las cuales cobra sentido la existencia de las villae ${ }^{7}$. Este condicionante opera claramente en el Alto Imperio, pero creemos que no debe excluirse completamente en el Bajo Imperio, momento en el que florecieron la mayor parte de los establecimientos conocidos.

Una vez expuestas estas consideraciones previas conviene precisar el alcance del análisis que realizaremos y que tendrá como punto de partida la distribución de las villae que conocemos en la Península, y los principios por los que se rige su distribución en torno a núcleos urbanos, vias naturales de comunicación y caminos.

Más que una exhaustiva enumeración de establecimientos e indicios de ellos, nos interesa obtener impresiones significativas de la estructura de ocupación del campo a través de villae en las áreas geográficamente más representativas del conjunto peninsular. El objetivo es descubir los principios a los que responde la expansión de las villae en las diferentes fases de la Hispania Romana; la organización del espacio que delatan, su articulación en torno a centros urbanos, o su papel de organizadores del espacio rural en ausencia de núcleos urbanos. Ese estudio no puede abordarse con la misma perspectiva de éxito en todas las regiones peninsulares, sino que depende de que los testimonios que poseamos sean suficientes como para trascender del puro ejemplo y ser, al contrario, parte de un contexto que podamos interpretar y explicar.

La organización del espacio que las villae representan son un reflejo de una forma de organización económica también y, por ello es de gran importancia relacionar el tipo de implantación de las villae en los diferentes periodos de la historia de la Hispania romana y en las diferentes regiones peninsulares.

LeVeau, Ph., establece en la organización del territorio de una ciudad romana, que los propietarios, habitantes de la ciudad, organizan el campo concretando este proceso en el establecimiento de una red de villae con las que se define el área de influencia de la ciudad. En el caso de Cesarea de Mauritania, establece ese radio en $15 \mathrm{~km}$. Veáse “Une ville et ses campagnes l'exemple de Caesarea de Mauretanie". Colloque Villes et campagnes dans L'Empire Romain. pág. 86 ss. Como referencia comparativa ver más adelante los resultados de E. Cerrillo y Fernandez Corrales. 
Para nuestros propósitos, una división establecida con base en la división provincial republicana es sumamente útil para analizar la implantación de las primeras villae y descubrir los principios rectores por los que tiene lugar el proceso de romanización del campo. La división republicana en dos provincias Ulterior y Citerior corresponde a unos territorios cuyos límites se ensanchan con el progreso de la conquista pero que tienen una base muy sólida, sobre la que el proceso de romanización se desarrolla tempranamente por ser la base de operaciones de los conquistadores. Esa base, que en la provincia Ulterior corresponde al valle del Gaudalquivir y en la Citerior a la cornisa levantina, especialmente el Nordeste catalán y el Valle del Ebro, constituye dos unidades diferenciadas que presentarán características especiales desde el principio por ser las que, como es sabido, más rápida y profundamente asimilan las influencias de la romanización, y la aproximación con el modelo romano que no se da entre las estructuras políticas, sociales - la urbanización y la ciudad como célula de organización política-, y económica del mundo indígena -producto de un proceso de siglos y contactos con las colonizaciones que hizo que las poblaciones indigenas de las regiones citadas poseyese unas técnicas agrícolas y artesanales perfectamente comparables con las de las sociedades mediterráneas avanzadas - tenia unas condiciones muy favorables, de ahí que incluso en época republicana tengamos muestras de una implantación de villae en áreas como Cataluña y el Valle del Ebro, aunque no en el Valle del Guadalquivir. Su individualidad se traducirá administrativamente en los tiempos de Augusto en la provincia Baetica, que comprende sustancialmente el Valle del Guadalquivir, y los conventos de la Hispania Citerior o Tarraconense: Caesaraugustano y Tarraconense.

Para el resto de la península, el proceso de expansión de la villa no comienza sino en distintas fases del siglo । d.C. y es en el siglo siguiente, el II, cuando el proceso llega a su madurez. Esas amplias regiones, en las que haremos una distinción entre las correspondientes a la provincia imperial de Lusitania, los conventus de la Hispania Citerior que abarcan la Meseta - Cluniense y Carthaginense-, y los del Norte y Noroeste Peninsular, además de presentar unos ritmos diferentes de asimilación y una romanización con unas características diferentes al modelo mediterráneo bético o levantino, mostrarán unas formas particulares de estructuración del campo y de su economía que explican la forma y el papel que las villae jugarán en el Alto y el Bajo Imperio.

Nuestra opinión es que las villae del Valle de Ebro, del Nordeste peninsular y las del Valle del Guadalquivir deben entenderse dentro del contexto común típico de Italia, caracterizado por la íntima relación que 
entre ciudad y campo existe; la villa en Italia es un producto de las clases aristocráticas urbanas que adquieren propiedades y crean una estructura de explotación de esas propiedades en las que el conjunto de edificaciones que conforman la villa es el ineludible centro. No se concibe la villa sin una ciudad alrededor de la cual gravita la vida de su propietario, que de hecho comúnmente tiene en ella su residencia, y forma así una parte del esquema de ocupación del territorio, en el que el núcleo urbano será el centro organizador. En el plano económico, esa situación se traducirá en una orientación de parte de su producción a abastecer las necesidades urbanas, y este modelo se extenderá en las demás áreas peninsulares en bastantes zonas que podemos reconocer a través de la explotación arqueológica, como en Celtiberia -en torno a ciudades como Uxama- o en las tierras ricas de Lusitania que desde Mérida, su capital o desde otras ciudades que surgen como centros de conventus o que prosperan con la paz.

Debemos insistir también en la evidente continuidad que en muchas áreas suponen las villae respecto de formas de hábitat indígenas anteriores; continuidad que podemos comprobar en Cataluña, en Celtiberia, y en la propia Gallaecia, como parte de un proceso de transformación a gran escala de las estructuras anteriores ${ }^{8}$.

Sería una pretensión excesiva integrar todos los establecimientos conocidos en una estructura de ocupación del territorio según los principios que acabamos de exponer. Una empresa de ese orden desbordaría los objetivos de este trabajo y tendrá que ser el producto de años y esfuerzos de investigación llevada a cabo de manera interdisciplinar por equipos de trabajo de composición amplia y que integre perspectivas arqueológicas e históricas ${ }^{9}$. Más modestamente, aspiramos a esbozar unos modelos aplicados sobre una serie de áreas determinadas que puedan servir de patrón a seguir para las demás. Para la elaboración de esos modelos las zonas a seleccionar serán aquellas en las que podamos establecer una correlación estrecha entre estructura urbana, implantación de villae y existencia de una red de comunicaciones que sea exponente de una transformación del espacio y de una conexión con centros provinciales o con Roma; vías terrestres, fluviales o puertos maritimos.

- Véase bibliografía en nota 1

${ }^{-}$El modelo a seguir es el que representa la exploración de algunas regiones de Italia, como Etruria Meridional, por investigadores vinculados a la British School en Roma o por equipos italianos como los de Carandini. 
Una base para emprender el estudio de la organización del espacio rural debería ser el análisis de las huellas de centuriaciones que se conservan en la península, que son un signo indiscutible de una acción realizada por la autoridad romana y que tiene lugar en circunstancias diversas, aunque sea en el marco de la fundación de una colonia cuando resulte más normal. El estudio de las centuriaciones en la Península lbérica, sin embargo, está poco avanzado; las únicas áreas en las que se ha emprendido su análisis son el Valle del Gaudalquivir, con centuriaciones como las de Carmona, la campiña de Córdoba, Ulía o Baza, o las de Elche y Mérida ${ }^{10}$, ciudad ésta para la que son también de utilidad las referencias que en los gromatici veteres (Hyginus, concretamente) se hacen para comentar aspectos de su centuriación como las parcelas inusualmente amplias con las que fueron recompensados sus primeros pobladores ${ }^{11}$. Pero, como señala J. C. Gorges, son muy hipotéticas una serie de centuriaciones que se han tratado de rastrear en el SE peninsular ${ }^{12}$. Es en estos casos especiales en donde podemos esperar encontrar una ordenación del espacio rural según un modelo calcaldo completamente del que acuñó la tradición colonial romana de Italia. Los estudios de Ponsich y E. Cerrillo para Carmona y Mérida, y Ramos Fernández sobre el territorio de Illici muestran, efectivamente, que la división del territorio de esas ciudades responde a las normas de los agrimensores y la implantación de villae se adapta a esas unidades de explotación que nacen del reparto fundacional de la colonia y el papel del núcleo

${ }^{10}$ BALIL, A., "Centuriatio. Observaciones sobre la parcelación y agrimensura romanas y su reconocimiento", Estudios Clásicos, V, 1960, págs. 247 y ss; es una breve pero muy clarificadora introducción sobre los problemas teóricos de la agrimensura. Para ejemplos de centuriaciones: Estudios sobre centuriaciones romanas en España. Madrid-Valencia 1974. De los estudios contenidos en el volumen destacaremos, sobre todo: GonzálVEz PÉREz, V., "La Centuriatio de Ilici». págs. 101-113, y Rossello VERGER, V. M., “El catastro romano en la España del Este y del Sur" págs. 9-31. También sobre la centuriación de llici: Ramos FERNANDEZ, R., "Las villas de la centuriación de llici", en Symposium de ciudades augústeas. II. Zaragoza 1976, págs. 209-214. En la Bética: PoNSICH, M., Implantation rurale au Bas-Guadalquivir, dedica especial atención al caso de Carmona, págs. 223-4. Véase también Cortijo Cerezo, M. ${ }^{a} \mathrm{~L}$., "La Centuriatio Vliense". I Congreso Peninsular de Historia Antigua (1986), vol. II. Santiago de Compostela 1988, págs. 333-334. Sillieres, P., “Centuriation et voie romaine au sud de Merida: contribution a la delimitation de la Betique et de la Lusitanie", MCV, XVIII, 1982, págs. 437-448. GoRGES, J. C., "Centuriation et organisation du territoire: Notes preliminaires sur l'exemple de Merida", Colloque Villes et campagnes dans l'Empire Romain. Aix-en-Provence 1982 (1980), págs. 101-10. Cerrillo Martin DE CACERES, E., La vida rural romana en Extremadura. Cáceres 1984. También puede seguirse los trazos de una posible centuriación en Sevilla. Ver: Sillieres, P., “Prospections le logn de la Via Augusta", Habis, 8, 1977, págs. 334-5.

1 Ver infra: nota 52.

12 Gorges, J. C., Les villas hispano-romaines, pág. 95. El ejemplo que expone es precisamente el volumen de Estudios de centuriaciones romanas en España. Valencia 1974. 
urbano como centro de una compleja estructura de ocupación del territorio se hace más patente.

No debemos olvidar que los casos como los citados, en los que hubo en un determinado momento una reordenación del territorio y del hábitat, motivado por la instalación de colonos, son una excepción en el conjunto peninsular. La romanización en la mayor parte de Hispania tuvo lugar sin que la presencia organizada de colonos foráneos viniese a trastocar bruscamente las estructuras urbanas y las de ocupación del campo. Por ello el objetivo a cumplir es descubrir los cambios que la imposición del dominio romano y su administración promueven o imponen en las propias comunidades indígenas y en sus estructuras de organización del espacio y de propiedad de la tierra, ya que los principios de división del espacio que en un principio se aplicaban por la autoridad romana al ager publicus para instalar veteranos, fueron asumidos después por municipios o núcleos menos importantes incluso que así completan su romanización incorporando los principios de división de la tierra ${ }^{13}$. En el marco de esos cambios se hará posible la aparición de un signo tan netamente romano como es la villa, como núcleo de vertebración del espacio rural y como centro regulador de la economía agraria.

\section{DISTRIBUCIÓN REGIONAL}

Una vez expuestos en las líneas anteriores los factores que van a guiar nuestro análisis procederemos a un examen particularizando la realidad del papel de la villa en la organización del espacio rural, seleccionando tres grandes conjuntos regionales. Nuestro propósito es estudiar las áreas en las que la concentración de las villae es más densa y poner en relación esa concentración con factores que favorezcan su desarrollo.

A partir de los datos ya expuestos es evidente la existencia de unos patrones de distribución de las villae variables en función de diversas circunstancias y que nos muestran situaciones diferentes en las distintas regiones peninsulares. Nuestro propósito en este lugar es analizar en detalle los principios que sigue la implantación de las villae en una serie

13 Balil, A., "Centuriatio...", Estudios Clásicos, V, 1960, pág. 356. Rossello Verger, V. M. "El catastro romano en la España del Este y del Sur", Estudios sobre centuriaciones romanas en España, pág. 11. 
de áreas regionales peninsulares y delinear unos modelos de implantación rural correspondientes en los que las villae se inserten, y permitan medir el impacto que este modelo ejerza sobre las formas indígenas anteriores. Para ello analizaremos tres grandes áreas, como antes señalamos, que serán: 1. NE peninsular: Cataluña y Valle del Ebro fundamentalmente. 2. Valle del Guadalquivir, y 3. Mérida y su región.

\section{Organización del espacio rural en el área del NE peninsular}

En el Alto Imperio podemos individualizar varias zonas de implantación de villae desde épocas tempranas, pero únicamente en Cataluña y el Valle del Ebro se puede demostrar que el proceso comenzase en el siglo $\|$ o el I a.C., per más que estos precedentes, signo de una implantación de elementos foráneos durante la República, nos interesa la forma que a partir de la época de Augusto toma el patrón de dispersión de las villae por el territorio y el modelo de articulación del espacio en el que actúan villae, asentamientos indigenas y ciudades. La franja costera catalana y el Valle del Segre y sus afluentes son las áreas que mejores perspectivas ofrecen para su estudio por la abundancia de los establecimientos descubiertos y porque éstos están en una clara relación con una estructura urbana que bajo Roma alcanza un gran desarrollo, y además se insertan en una evolución del poblamiento rural de la que podemos reconstruir los rasgos fundamentales. Por último debe señalarse la base económica que en esta área fomentó el desarrollo de las villae, que es la expansión del cultivo de la vid, que alimentó unas corrientes de exportación que alcanzarian Roma ${ }^{14}$.

Tanto en el Valle del Segre como en el litoral barcelonés los indicios que poseemos apoyan la existencia de una relación estrecha entre los patrones de habitat indigenas y las villae romanas que aparecen como el elemento continuador. Pita Mercé, en el Valle del Segre y sus afluentes muestra que la villa representa una superación del hábitat ibero concentrado en cimas de montañas y expresión de unas circunstancias de inseguridad en las que la defensa era un elemento promordial para erigir

14 Vid: Pascual, R., "Centros de producción y difusión de un determinado tipo de ánfora", Can, VII. Barcelona 1960, págs. 334-335. Idem, "Acerca de la fabricación de ánforas", Ampurias, XXX, 1968, págs. 237-248. Idem, "Algunos aspectos del comercio antiguo según las ánforas", PLAV, 5, 1968, págs. 67-69. TCHERNIA, A., “Les amphores vinaires de la Tarraconaise", $A E A, 44,1971$, págs. 38-85; Idem, Le vin de l'ltalia romaine. 
un poblado, en favor de un nuevo patrón que permite la ocupación de las tierras más bajas y fértiles. Aparece claro en el plano físico el papel sustitutivo de la villa por el antiguo poblado, como en las cercanías de Barcelona, y como se repetirá en áreas como la de Uxama en Celtiberia y que, como veremos parece vislumbrarse en la Gallaecia. J. Guitart en su estudio sobre Baetulo señala esa evolución del modelo de habitat indígena concentrado al romanizado, aunque no se pronuncia sobre como actuaron los mecanismos de cambio. Sin embargo considera la instalación de romanos en un oppidum civium romanorum, entre fines del siglo ॥ a.C. y principios del । a.C. como factor que debió influir en esa evolución ${ }^{15}$. Es de especial interés por lo que representa de modelo indicativo de la realidad de la región costera el trabajo de $M$. Prevosti en los territorios contiguos de lluro y Baetulo. Esta autora al seleccionar unas áreas restringidas trasciende las generalizaciones obligadas por la naturaleza de los datos en regiones más amplias y su limitación en el territorio de estudio permite contrastar modelos genéricos propuestos anteriormente para la región catalana. Especialmente interesantes son sus conclusiones respecto a la relación estrecha entre ciudad y campo: las dos ciudades de lluro y Baetulo articulan, centrándola, la implantación rural romana, que es más densa en el área costera en la que esas dos ciudades se asientan y que aparecen como centros económicos de raíz agraria organizando una comarca muy fértil desde el punto de vista agrícola ${ }^{16}$.

El sistema de propiedad en el área catalana parece caracterizado por el predominio de la mediana propiedad, y esta impresión encuentra una confirmación en el área estudiada por M. Prevosti. La concentración de establecimientos rurales en un territorio reducido no deja margen para la gran propiedad; el paisaje rural se caracteriza por la existencia de muchas villae, de las que pocas son muy lujosas, e incluso éstas no disponen de extensión de tierras suficiente como para catalogarlas de latifundiarias ${ }^{17}$. Esa desproporción entre las dimensiones de villas como Torre Llauder y la extensión de tierra de que disponian es muestra probable de una propiedad absentista en manos de familias que en Tarraco o Barcino ejercian funciones y tenían su residencia permanente, de modo

15 Guitart, J., Baetulo. Badalona, 1976, págs. 241-2.

16 Prevosti, V. M., Cronologia i poblament rural à l'àrea rural de Baetulo. Badalona 1981, pág. 278.

1 Prevosti, M., op cit., págs. 281-2, considera que a la vista de la densidad de los establecimientos y su distribución en el territorio, la extensión de la propiedad media fuese de unos 109 iugera, o 100, en una economía agraria caracterizada por la importancia de la vid. 
que sus villae en estas áreas tendrían una orientación doble; de descanso y de explotación ${ }^{18}$.

Queda en pie el problema del origen de esta estructura de la propiedad, que, en el caso de Baetulo, J. Guitart trata de atribuir a una hipotética instalación de veterano de ejército de Mario, con una poco sólida base ${ }^{19}$.

En Emerita y en el Bajo Guadalquivir nuestro interés se basa en el proceso de organización y ocupación del territorio subsiguiente a la implantación colonial romana, que se ordena a partir de centuriaciones. En estos lugares la relación entre hábitat rural prerromano y hábitat romano debe plantearse desde otras perspectivas diferentes a las regiones anteriormente citadas, pues el impacto que sobre las estructuras indígenas supone la romanización es de muy diferente naturaleza, al tener lugar no una implantación progresiva de elementos foráneos en un medio indígena al que van romanizando, o una adsignatio en beneficio de la población indígena que, como señala $C$. A. Ferreira de Almeida se produciría en Gallaecia ${ }^{20}$, sino una implantación de población nueva, veteranos de guerra o civiles, que se asienta con unos patrones nuevos que rompen completamente con las realidades anteriores; además los efectos de esas influencias también se trasladan a las poblaciones indigenas que cuando reciben un estatuto municipal puede reorganizar junto con sus instituciones su espacio territorial ${ }^{21}$. Precisamente en el Valle del Guadalquivir y en las tierras lusitanas regadas por el Guadiana esa política colonial Ilevada a cabo por César y Augusto, tiene unos efectos más notorios, como

${ }^{18}$ Prevosti, M., op cit., pág. 280.

19 Guitart, J., Baetulo. Topografía, arqueología, urbanismo e historia. Badalona 1976. págs. 239-43. Pasando por alto el verdadero alcance de las Leges Appuleiae por las que se aprobaba el establecimiento de veteranos de Mario (NiCOLET, C., Rome et la conquête du monde méditerranéen, pág. 136-7 y LASSERE, J. M., Ubique Populus, creen que tuvo trascedencia tanto en África (Lassère, Nicolet), como en la Narbonense (Nicolet). Brunt, 577-580, restringe su efecto, y excluye a ciudadanos romanos como beneficiarios, Italian Manpower, Oxford, 1971, el autor reconoce la inexistencia de evidencia documental de que el NE de la península ibérica haya sido objeto de esas leyes: GUITART, op cit,, pág. 214. Por ello aunque Prevosti, M., asuma esta supuesta implantación de colonos de Mario, op cit., pág. 282, no se incrementan los argumentos que la justifiquen.

${ }_{20}$ Ferreira de Almeida, C. A., "O castrejo sob o dominio romano" en G. Pereira (ed). Estudos de Cultura Castrexa e de Historia Antiga de Galicia. Santiago 1986.

${ }^{21}$ Es el caso de Carmo, que recibe su condición de municipio latino desde Augusto: Galsterer, H., Untersuchungen zum römischen Städtewesen auf der iberische Halbinsel. Berlín 1971, pág. 11, nota 34, o quizás desde Calígula (Thouvenot, Essai sur la Bétique..., pág. 196), y donde PoNsicH, Implantation rurale, págs. 223-4 reconoció la existencia de una centuriación cuyo origen fija en el momento en el que la promoción municipal se haya llevado a cabo. 
señalaba García y Bellido ${ }^{22}$. Estos diferentes modelos, pues, son para nosotros, marcos de referencia fundamentales en nuestro estudio.

\section{Organización del espacio rural en el valle del Guadalquivir}

Sobre algunas de las áreas del Valle del río Guadalquivir, la confluencia de una serie de circunstancias trascedentales de tipo histórico hace que tengamos una realidad que ilustra un modelo de ocupación en el que la mezcla de tradiciones antiguas de una sociedad ya avanzada como la turdetana, que había incorporado influencias coloniales, y de influencias tempranas de Roma, por lo precoz de su conquista, adquiere su conformación definitiva después de los trastornos de las guerras que enfrentaron a cesarianos y pompeyanos. César y, después Augusto, con sus decisiones contribuyeron a establecer un modelo de ocupación del territorio, en el que la implantación de importantes contingentes de colonos procedentes de Italia y de sus ejércitos sería determinante.

El caso de la Bética, en especial del fértil valle del río Guadalquivir, nos ofrece, pues, un ejemplo a analizar caracterizado por una romanización profunda e inducida por Roma con medidas como las indicadas. Así Strabón explica la romanización de la región en bastante medida por la cantidad de romanos que viven entre ellos. Pero además nos ofrece un ejemplo caracterizado por la continuidad del desarrollo histórico a través de todo el período de imperial ${ }^{23}$. Y el problema, la continuidad, estará presente de una manera constante en la panorámica que realizemos por la Península.

22 GARCIA y Bellido, A., “Del carácter militar activo de las colonias romanas en la Lusitania y regiones inmediatas”, Trabalhos de Antropologia e Etnologia, 17, 1959, págs. 299-304.

${ }^{23}$ En la Bética, como en ninguna otra parte de la península puede comprobarse, a pesar de la deficiente información arqueológica que poseemos, la inexistencia de una ruptura entre el Alto y el Bajo Imperio en sus edificaciones rurales. Tanto el inventario de villae realizado por GoRgEs: Les villas hispano-romaines, como los yacimientos referidos por PoN$\mathrm{SICH}$, M., Implantation rurale antique sur le Bas Guadalquivir. Madrid 1974, muestran que en la inmensa mayoría las villae desarrollan ininterrumpidamente su existencia entre el siglo । a. C. y el siglo IV, siendo previsiblemente las invasiones del 409 el único factor destructor que padecieron de forma insuperable. En la costa de Málaga, el problema es diferente; es la naturaleza expresada por movimientos telúricos la que puso fin a sus establecimientos en el siglo iv. 
La obra de M. Ponsich ${ }^{24}$ es el mejor ensayo de reconstrucción del paisaje rural antiguo de la Bética aunque esté reducida geográficamente, a las tierras ribereñas del Guadalquivir y no sea el fruto del desarrollo de una actividad arqueológica fructifera, sino el producto de un trabajo de prospección sin posibilidades de profundizar en el estudio de los establecimientos. Los trabajos de G. Bonsor, que lo precedieron a fines del siglo pasado y comienzos del actual, muy meritorios, no dieron lugar a una continuidad en la investigación y el de $R$. Thouvenot, marca un eslabón intermedio ${ }^{25}$.

El estudio de M. Ponsich muestra la importancia que en la implantación rural antigua tiene la geografía de esta región; en especial la influencia del río y las condiciones edafológicas de las dos márgenes del Guadalquivir. El conjunto de esas condiciones explica que Sevilla esté cerca del punto extremo a partir del que es imposible la colonización de tierras en el tramo inferior del río. Precisamente el conjunto representado por las aglomeraciones de Itálica e Hispalis nos representa dos polos, cabeza uno, Itálica, de una rica región agrícola: el Aljarafe, que en la antigüedad tenía relación directa con el río (éste pasaba por Itálica), e Hispalis, el principal puerto, llamado a centralizar toda la actividad comercial posteriormente cuando el río se aparte definitivamente de la ciudad vecina. En el Aljarafe la ocupación, densa y con una raíz antigua, debido a la fertilidad del terreno, en el que prospera sobre todo el olivo, se tradujo en la época romana en un número elevado de villae, que según Ponsich sirvieron como base para la formación de aldeas, a través del período árabe, algunas de las cuales conservan el nombre de sus posesores romanos ${ }^{26}$. La continuidad, a través del período árabe hasta los tiempos actuales del modelo de explotación representado por la villa es un hecho.

Las condiciones geográficas imponen unas pautas de asentamiento y ciertas fórmulas de ocupación del espacio son constantes a través de las edades por causa de ellas. En el Guadalquivir las condiciones principales a señalar son para su curso inferior la disimetria de sus márgenes, que hace que la derecha presente caracteres favorables para el asenta-

${ }_{24}$ PONSICH, M., Implantation rurale antique sur le Bas-Guadalquivir. Madrid 1974; Implantation rurale antique sur le Bas-Guadalquirvir, II. Paris 1979; Implantation rurale antique sur le Bas-Guadalquivir, III. Madrid 1987; "Prospections archeologiques dans la vallee du Bas Guadalquivir", MCLV, 8, 1972. "Structure rural et paysage antique du Bas-Guadalquivir”, Caesarodunum, 13, 1978, págs. 240-53.

${ }_{25}$ Thouvenot, R., Essai sur le province romaine de la Betique. Paris 1973.

${ }^{26}$ PONSICH, Implantation rural, pág. 60. 
miento de núcleos urbanos, por su mayor altura y solidez, mientras que la orilla izquierda, más baja y expuesta a las inundaciones repele la instalación humana. Por esa razón cobra tanta importancia la existencia de alturas como Los Alcores, que dan personalidad a la comarca de Carmona y de valles de afluentes que drenan las tierras llanas que el río deja a su izquierda como el del Corbones. Como en la región de Itálica el asentamiento humano tiene un pasado prolongado en la región de Los Alcores, por sus condiciones propicias de situación y de fertilidad, además esas alturas dominan una comarca llana, la Vega de Carmona, que desde los tiempos prerromarios dio lugar a una explotación cerealista a gran escala, de la que los indígenas turdetanos sentaron las bases, junto con elementos coloniales de origen púnico que dejarian su huella durante bastante tiempo ${ }^{27}$.

Ponsich señala que en los tiempos prerromanos la explotación agrícola sería llevada a cabo "par des collectivités qui ne vivaient pas sur le sol même qu'elles exploitaient, mais plutôt dans des aglomérations voisines»" ${ }^{28}$. En suma el patrón de hábitat sería concentrado en función de la existencia de puntos de agua, y el aprovechamiento de las tierras de la Vega no sería sistemático; esto contrasta con el periodo imperial, tras la reordenación del espacio agrícola de Carmona. Ese proceso supuso la parcelación de la Vega y la implantación de pequeños y medianos propietarios que intensificaron la ocupación y explotación de la llanura, mientras que en la zona de colinas de los Alcores y las terrazas la continuidad entre el patrón de ocupación prerromano y el romano es más notoria, ocupación densa con multitud de granjas y villae dedicadas al cultivo del olivo. Sin embargo la escasez de agua dulce en la llanura de la Vega de Carmona impidió que se diese el paso a un hábitat disperso; las huellas de una ocupación rural más densa, más que a villae o granjas, corresponden, según Ponsich, a cercados o cabañas ${ }^{29}$.

El trabajo en el campo no podía ser más que estacional y únicamente obras de retención de agua de lluvias y crecidas permitian satisfacer la necesidad de agua para bestias y hombres durante los trabajos ${ }^{30}$ en

${ }^{27}$ Gonzalez Wagner, V.E.C., Fenicios y Cartagineses en la peninsula ibérica. Madrid 1983, pág. 46-7, recoge la evidencia de una colonización agricola intensa debida a los propios fenicios desde el siglo vi, que en el Guadalquivir se implantarian entre la población indígena. PONSICH: Implantation rurale, pág. 223, señala que ya en la época ibero-punica las explotaciones de los Alcores sería en grandes explotaciones organizadas en granjas que precederian a las mayores y mejor acondicionadas villae.

${ }^{28} \mathrm{PONSICH}$, Implantation rurale, pág. 223.

${ }^{29} \mathrm{PONSICH}$, Implantation rurale, pág. 287

${ }^{30} \mathrm{PONSICH}$, Implantation rurale, pág. 224. 
esa inmensa y seca llanura durante el verano. Con todo, paradójicamente la oposición que caracteriza a la Vega, con respecto a los Alcores en su sistema de propiedad, sería el latifundismo de ésta, frente a la pequeña y media propiedad de la primera, y el modelo configurado definitivamente bajo el Imperio de explotación dual de cereales en la Vega y olivares en los Alcores persistirá al menos hasta el final del siglo IV; las invasiones debieron romper este patrón que los árabes no llegaron a restaurar, prefiriendo los olivares de las tierras altas ${ }^{31}$.

En el resto del valle del Guadalquivir las características de la organización del habitat siguen condicionadas por el papel del río como organizador del espacio geográfico y vía fundamental de comunicación. Así vertebra la comunicación entre las regiones mineras de Sierra Morena y las agricolas de sus dos márgenes permitiendo la existencia de una densa red de establecimientos rurales e industriales en sus orillas, especialmente la derecha, más a salvo de inundaciones y con lugares más propicios a la existencia de puertos y embarcaderos; en la izquierda arriba de Sevilla y hasta llegar a Córdoba solamente se contaban los puertos de Oducia=Tocina y Palma del Río, este último, que llegó a formar una importante aglomeración aunque no sabemos con qué ciudad antigua se debe identificar, estaba en la confluencia del Guadalquivir con el Genil y era la salida de una vasta y feraz región alrededor de Astigi, punto desde el que el Genil era también navegable ${ }^{32}$. Pero la ausencia de ciudades portuarias, señala Ponsich, no significa que las ricas tierras al sur del río careciesen de una salida hacia él; multitud de establecimientos en los que se fabricaban anforas dan fe de que los lugares de embarque eran muy numerosos y la estructura de los caminos rurales llevaba hacia estos lugares o portus que cumplian así una función fundamental en la circulación de los productos de las villae. Esos lugares de embarque no constituyeron puertos permanentes por culta de los cambios de curso del río ${ }^{33}$. Por las ciudades portuarias de la derecha se expedía el mineral, así como los productos agrícolas de las haciendas, que se recogian a través de la navegación estacional por los portus de la orilla izquierda; el tráfico regular de los primeros no era obstaculizado por el segundo, y la existencia de una industria de fabricación de ánforas en esos lugares es

${ }^{31}$ PONSICH, Implantation rurale, pág. 281-2, señala que el latifundismo tendría su base en los Alcores, pero que extendería su influencia sobre la Vega al preferir la erección de las granjas y villae en la línea de manantiales que pone en contacto ambas comarcas.

${ }_{32} \mathrm{PONSICH}$, "Structure rural et paysage antique du Bas-Guadalquivir". Caesarodunum. 13, 1978, pág. 246.

$33 \mathrm{PONSICH}$, «Structures rurales et paysage antique", pág. 245. 
consustancial a la explotación agrícola de grandes dimensiones. Hay que señalar que las tierras de la margen izquierda, más amplias y aptas para la agricultura a gran escala tienen la mayor densidad de establecimientos rurales e industrias de alfares; con una red numerosa de caminos rurales que convergen hacia centros urbanos de los que, sin embargo, no recogen mención alguna los autores antiguos. Los estudios de M. Ponsich muestran la densidad de la implantación rural, la extensión a tierras interiores del valie del Guadalquivir, no sólo a las orillas del río, y los diferentes criterios de organización espacial seguidos para la implantación humana a fin de explotar esas tierras, siempre explicables por las condiciones geográficas, pero que admiten unas fórmulas muy variadas: centuriaciones en unos casos, como el de la Vega de Carmona, distribuciones en dominios particulares levantados en función de los puntos de agua en otros ${ }^{34}$.

Una cuestión crucial, también desde el punto de vista de la organización del espacio, es el problema del latifundismo, o si se quiere, en general el de la repartición de la tierra en la antigua Bética. Desde el punto de vista de la estructura del hábitat y la organización del espacio, las transformaciones desde la época de Augusto parecen establecer una estructura compleja en la que tanto el latifundio como la mediana o pequeña propiedad tienen su lugar ${ }^{35}$. Esto se traduce por una parte en la expansión de las villae que se configuran como centros organizadores del espacio rural en zonas como los Alcores o el Alfaraque, áreas en las que el olivo tenia un gran arraigo. Las exploraciones arqueológicas de $\mathrm{M}$. Ponsich recrean una estructura en la que coexistirian la villa rústica extensa con granjas de tamaño mediano. Pero también muestra que en territorios como el de Carmona la expansión de la mediana o pequeña propiedad con la centuriación de su territorio no se tradujo automáticamente en una dispersión del hábitat que crease nuevas redes de ocupación del suelo.

${ }^{34} \mathrm{PONSICH}$, Implantation rurale..., págs. $288-9$; "Structure rurale et paysage ancienn", pág. 246 y ss.

${ }^{35}$ SANCHEZ LeON, M. ${ }^{a}$ Luisa, Economia de la Hispania Meridional, pág. 202, para la época de los Antoninos señala la coexistencia de mediana y gran propiedad, aunque con tendencia al incremento de ésta. Las opiniones han sido muy variables, sin embargo. Asi: Rostovzeff creía en el predominio del latifundio: Historia social y Económica del imperio Romano, I, 413-4, 421. BlAzQuez, Economia de la Hispania Romana, pág. 357, a la vista de la dispersión de la población, "la propiedad debia encontrarse muy repartida a juzgar de la concentración de colonias en territorios reducidos, que en los municipios debian existir muchos pequeños propietarios y que existian latifundios, pero nunca de la extensión de los de África". 
Señalemos que las posiciones defendidas respecto de la importancia del latifundismo en el valle del Guadalquivir suponen la existencia del fenómeno, pero sin que haya un acuerdo en señalar su importancia en el marco de la estructura de la propiedad y en la organización del espacio rural que este modelo supondría. Recordemos que Rostovtzeff señalaba que el latifundio era consustancial a la Bética ${ }^{36}$, y su importancia y naturaleza han sido señalados por otros muchos. J. Caro Baroja, J. M. Blázquez, A. Balil, M. Ponsich y R. Etienne, entre otros han considerado el latifundismo como un fenómeno presente en la región ${ }^{37}$, pero no de manera excluyente de otras formas de propiedad y tenencia de la tierra. Por lo demás a lo largo del Alto Imperio un nuevo factor, la expansión del dominio de propiedad imperial, se haría sentir cada vez más; ya con Tiberio que confiscó las propiedades de Sexto Mario, pero, sobre todo con la dinastía Severa que extendió las confiscaciones en la Península a raiz de la guerra civil del 197 d.C. Etienne además aborda el problema de la evolución del latifundio bético aunque de manera muy superficial, pues considera escaso el impacto de los repartos realizados con la coIonización de César y Augusto, ya que presupone que esos lotes acabaron absorbidos pronto en grandes latifundios y que los veteranos, pequeños y medianos cultivadores, al igual que sucediera en Italia los de Sila, fracasarian ${ }^{38}$. Discrepamos abiertamente de esta óptica, que el autor incardina además en un contexto ideal caracterizado porque «de petits lots ne pouvaient répondre à l'économie de marché". Igualmente su opinión de que la extensión de las grandes propiedades podría alcanzar de 1500 a $2500 \mathrm{Ha}$ no pasa de ser una hipótesis posible, pero sin apoyo documental o de otro tipo que la justifiquen ${ }^{39}$.

Las transformaciones que se aprecian en el modelo de ocupación del espacio y de propiedad del suelo desde los tiempos de Augusto, sobre cuya importancia, los datos mencionados nos dan suficiente muestra, pueden haber supuesto la entrada en juego de factores nuevos, sobre cuyo peso es difícil pronunciarse. Así, C. Domergue, enuncia una teoría explicativa del desarrollo de la economía agraria de la Bética en el siglo । d.C. partiendo de una transferencia de capitales de la minería a la

${ }^{36}$ Rostovzeff, Historia Social y Económica del Imperio Romano, 1, págs. 412-20.

${ }^{37}$ Caro Baroja, J., Los pueblos de España. Madrid, 1981, 3. ${ }^{a}$ ed., págs. 217-8. BlazQuez, J. M., EConomia de la Hispania Romana. Bilbao, 1978, pág. 357. PONSICH: "Structure agraire et paysage", pág. 241. ETIENNE, R., "Les problemes historiques du latifundium" (en "Structures agraires antiques dans la région de Séville». MCV, 8, 1972, págs. 622 y ss.). BaLIL, A., "Economía de la Hispania Romana (S. I-III)". Studia Archaeologica. 15, 1972

${ }^{38}$ ETIENNE, R., ibidem, pág. 623.

${ }^{39}$ ETIENNE, ibidem, pág. 626. 
agricultura; su razonamiento es que se puede relacionar la crisis que muchas explotaciones mineras sufren a mediados del siglo I a.C. con las consecuencias de la guerra civil del 49 al 45, y dado el pesado coste de volver a ponerlas en explotación, muchos negotiatores o sociedades pueden haber optado por invertir sus capitales en tierras ${ }^{40}$. Asi se explicaría, por una parte, el abandono de muchas explotaciones y, por otra, la plantación masiva de olivos que tendría su expresión en la irrupción del aceite hispano desde la primera mitad del siglo I d.C. en el Occidente romano ${ }^{41}$.

No negamos la probable indicencia de un fenómeno de características como las que refiere Domergue, pero, el mismo autor reconoce que falla la comprabación de su hipótesis en un punto tan importante como la continuidad entre marcas de lingotes y marcas de alfarero posteriores ${ }^{42}$, y la prudencia por ello invita a no exagerar la importancia de ese hipotético factor. Por lo demas la estructura de la sociedad y el reflejo que conocemos en el sistema de la propiedad, parece establecer la importancia de familias de origen itálico, pero sin que se mencione que su riqueza esté basada en las minas.

Sin embargo es más que probable que, como apunta Domergue ${ }^{43}$, la propiedad agraria no excluyese la de minas y de este modo en la explotación rústica, estuviese presente en muchos casos una fundición, en la que se transformaban los minerales extraidos en Sierra Morena, de la misma manera que se fabricaban las ánforas en las que se exportaban los productos de la finca. Creemos, en cualquier caso, que un capital de origen minero, de magnitud tan grande como para influir en el sistema de propiedad de la tierra, alterándolo sustancialmente no existió nunca; nos parece más razonable la sugestión de R. Etienne de que en todo caso, los propietarios de subsuelo lo fuesen también de tierra, que era la única garantía de su dignitas ${ }^{44}$.

${ }^{40}$ Domeroue, Claude, "Rapports entre la zone minière de la Sierra Morena et la plaine agricole du Guadalquivir à l'époque romaine. Notes et hypothèse". (Incluido en: "Structures agraires antiques dans la règion de Séville: Essai de problématique») $M C V, 8,1972$, pág. 619.

${ }^{41}$ Ibidem, pág. 620.

${ }^{42}$ Ibidem, pág. 621

${ }^{43} \mathrm{Ibidem}$, págs. 616-7. Analiza la anomalia supuesta por la presencia de escorias de fundición en lugares situados en la campiña, al Sur del Guadalquivir, lejos de las minas.

${ }^{44}$ ETIENNE..., lbidem, pág. 622. 


\section{Organización del espacio rural en el área de Mérida}

El caso de Mérida merece atención por su condición de asentamiento que nace de la nada y que organiza, según unos criterios impuestos por la autoridad central, el territorio adscrito a la colonia. Aquí se divide el territorio entre veteranos de guerra y siguiendo los principios de centuriación, con la originalidad de la extensión atribuida a cada lote, mucho mayor que la habitual ${ }^{45}$. El territorio adscrito a la nueva fundación tiene una extensión muy grande en las dos márgenes del Guadiana (un hito de delimitación del territorio se encontró en un lugar tan alejado como Montemolín, a $105 \mathrm{~km}$ al sur de Mérida, aunque tanto Wiegels, como García Iglesias y Silliéres consideran que se trataría del límite de un enclave emeritense en territorio bético ${ }^{46}$, no pudiendo exagerarse la extensión de territorio emeritense al Sur del Guadiana ${ }^{47}$ ) y el futuro de la ciudad estará además ligado a grandes destinos, ya que su papel de capital de la Lusitania se acrecentará en el Bajo Imperio con el de capital de la diócesis de Hispania de modo que estará llamada a convertirse en la principal ciudad romana de la Península a medida que pase el tiempo, y lo será en una región que, al contrario que la Bética, su inmediata vecina, no alberga una red de ciudades muy densa, y que hace caer bajo

45 Véase, Gromatici veteres: Hyginus Grom. Constitutio Limitum, pág. 135, 15ss., ed. Thulin. Sillieres, P., "Centuriation et voie romaine au Sud de Mérida. Contribution a la delimitation de la Betique et de la Lusitanie". MCV, 18, 1982, págs. 437-448; CORzO SANCHEZ, J. R., "In finibus emeritensium", Emerita Augusta. Actas del Bimilenario de Mérida; Cerrillo Martin de Caceres, E. La vida rural romana en Extremadura. Cáceres 1984, pág. 56; Garcia IGLESIAS, L., "Notas sobre el panorama económico colonial de Augusta Emerita», Revista de la Universidad Complutense de Madrid, XX, núm. 79, 1971, págs. 97-111.

46 SIlliéres, P., "Centuriation et voie au sud de Mérida", MCV, XVIII, 1982, pág. 436. señala que puede tratarse de un distrito minero atribuido a la colonia. Problema diferente es el que plantea el hito de Valdecaballeros, también a más de $100 \mathrm{~km}$ de Mérida, que puede estar en relación con la extensión del territorio de Mérida hacie el Este y Nordeste, que abarcaba a la propia Trujillo, (Turgalium), situada ésta a unos $90 \mathrm{~km}$, como prefectura, al menos en sus primeros tiempos (Hyginus grom.: Constitutio limitum, 135, 15-136, 10).

47 Garcia Bellido, A., "Las colonias romanas de España», AHDE, 29, 1959, págs. 487 88; WIEGELS, R., "Zum territorium der augusteischen Kolonie Emerita", Madrider Mitteilungen, 17, 1976, págs. 278-80; Garcia IGLESIAS, L., “El Guadiana y los límites comunes de Bética y Lusitania". Hispania Antiqua. 2, 1972, pág. 165; SILLIERES, P., "Centuriation et voie romaine au sud de Mérida", MCV, XVIII, 1982, págs. 438-9. Todos coinciden en que los límites del territorio de Mérida al sur del Guadiana irian al norte de las ciudades de Nertóbriga $=$ Valera la Vieja, cerca de Fregenal de la Sierra; Curiga =cerca de Monesterio, Contributa = cerca de Medina de las Torres y Regina=Reina, que pertenecian a la Bética; o sea que hacia Los Santos de Maimona, cerca de Zafra, a poco más de $50 \mathrm{~km}$ al sur de Mérida estaria la divisoria. Asi se resalta el carácter aislado del Hito de Montemolín, adonde no podía llegar el territorio emeritense de manera continua. 
su poderosa influencia a otras fundaciones como Metellinum, Norba, que al lado de un núcleo tan poderoso llevan una existencia modesta ${ }^{48}$.

La organización del espacio en el área de Mérida, pues, debe estudiarse como un proceso inducido por decisiones politicas de gran alcance que hace que la relación entre patrón de hábitat romano y hábitat indigena sea aún menor que en la Bética $y$, por supuesto, que el NE peninsular. Estudios como el de M. del Amo sobre el ager de Medellín muestran que el sistema de villae dispersas conformaba el patrón de ocupación y explotación, creándose un panorama caracterizado por la mediana propiedad, en contraste con el latifundismo anterior. La época augústea, hacia fines de su reinado es el momento en el que se comienza a producir ese fenómeno, que se completaría en el resto del siglo । d.C. ${ }^{49}$.

El caso de Mérida presenta caracteres más complejos. Por una parte es un fundación realizada con veteranos de las guerras cántabras, conforme a unos mecanismos que en el último siglo de la República se aplicaba frecuentemente como premio a los licenciados de los ejércitos y que con César y Augusto alcanzarón una intensidad máxima y que se hicieron sentir en suelo provincial. La consecuencia lógica de estas fundaciones, que eran concebidas con una finalidad estratégica preferente ${ }^{50}$, era la creación de nuevos propietarios de tierra, o la restauración de ellos. Pero la consecución de este logro parece más discutible. Dejando a un lado el problema de la escasa entidad de los lotes que se concedian en las colonias fundadas en Italia; el problema de las colonias en la península puede verse a la luz de la capacidad de atracción que estas tierras provinciales podian ejercer sobre los beneficiarios de los repartos. En el caso de la Bética esa atracción que ejercia sobre colonos foráneos está fuera de toda duda, pero en el caso de lugares como Lusitania es más discutible, teniendo en cuenta el pasado conflictivo de estas tierras y las recomendaciones de Varrón que desaconsejaba invertir en tierras en ella, a causa de la inseguridad ${ }^{51}$. Todas estas circunstancias pueden contribuir a explicar la peculiar conformación tan extensa del territorio de la nueva colonia, así como la extraña generosidad derramada en los

48 AMO Y DE LA HERA, M. del, “Estudio preliminar sobre la romanización en el término de Medellín (Badajoz). La necrópolis del Pradillo y otras villas romanas", Noticiario Arqueológico Hispano, 2, Arqueología, 1973, págs. 51-130.

49 AMO, M. del, ibidem, págs. 129-30.

5o NiCOlet, C., Roma y la conquista del mundo mediterráneo. Nueva Clio. Brunt, Conflictos sociales en la República romana. Garcia y BELlido, A., "Del carácter militar activo de las colonias romanas de la Lusitania y regiones inmediatas".

51 VARRÓN: R. R., I, 16, 2. 
repartos individuales a los nuevos ciudadanos. La función estratégica de esta colonia en unas condiciones de relativa frontera, exigirian especiales incentivos para que sus habitantes arraigasen en el lugar. E. Cerrillo señala tres repartos que deben corresponder a sucesivas instalaciones de veteranos y que los criterios de reparto varían con el tiempo; una primera centuriación preveía parcelas de 200 iugera $(50,4 \mathrm{Ha})$, mientras que Hyginus informa de que la asignación fue de 400 iugera $(100,8$ $\mathrm{Ha})^{52}$, lo que contrastaba con otras asignaciones consideradas como generosas como la que en su día se realizó en Cremona, que era, según Hyginus el agrimensor, de 210 iugera. Esta generosidad servía para fijar a unos habitantes sujetos a unas condiciones dificiles, pero la argumentación por parte de A. Balil, que sigue E. Cerrillo, de que existiria un abandono del campo por no resignarse los veteranos a reanudar la vida de campesinos, no nos parece muy aceptable dada la falsedad de esa imputación en los casos de los campesinos beneficiarios de la obra de los Graco, de los que no hay motivo para dudar de su aptitud para la vida en el campo, o de los veteranos de Sila, que fueron instalados en condiciones extremas y con la oposición de la población anterior expropiada ${ }^{53}$. En todos estos casos se olvida, a veces, que la extracción rural es la predominante en todo tiempo en los ejércitos romanos, y que la vuelta al campo es una reivindicación presente en los soldados movilizados, que hace sentir especialmente durante las Guerras Civiles.

La realidad emeritense, a la vista del desarrollo de la ciudad y de los signos de densa ocupación del espacio rural que conocemos, muestra el

52 Hyginus Grom.: Constitutio limitum. Ed. Thulin, pág. 135, 15 ss: “In Italia triunviri iugerum quinquagenum, aliubi ducenum; Cremonae iug. CCX; divus Augustus in Beturia Emeritae iug. CCCC, quibus divisionibus decumani habent longitudinis actus $X L$, cardines actus XX, decumanis est in orienten".

Veáse también, URBico, Agennio, De controversis agrorum, 44,5-21, que toma fundamentalmente partes de Frontino pérdidas, habla de hasta tres repartos consecutivos sin que se consiguiera asignar todo el espacio disponible, y de que los repartos se hicieron más en los bordes del territorio que en las proximidades de la ciudad y en los márgenes del Guadiana, hecho que ya A. García y Bellido, atribuyó al carácter militar de las colonias, que servian ante todo como exponente de la fuerza y presencia de Roma en un territorio extraño al que no se pretende romanizar sino controlar. GARCIA y BELLIDO, A., "Del carácter militar activo de las colonias romanas de la Lusitania y regiones inmediatas", pág. 299 ss. Cfr. GarCiA IGLESIAS, L., "Notas sobre el panorama económico colonial de Augusta Emerita", Revista de la Universidad de Madrid, XX, núm. 79, pág. 98.

${ }_{53}$ Cerrillo, E., La vida rural en Extremadura romana, pág. 56; BallL, A., «Riqueza y Sociedad en la España Romana (siglos III-1 a. C)", Hispania, XXV, 1965, pág. 354-5. Consideramos más correctas las opiniones de BRUNT: Conflictos sociales en la República romana, pág. 137-8, 146-7, 159, 189, o NiCOLET: Rome et la conquète du monde méditerranéen, vol. 1, pág. 138-9. 
evidente éxito final del asentamiento y el arraigo que alcanzó esa población instalada por Augusto y en la que hubo un último reparto de tierras en los tiempos de Otón ${ }^{54}$. Hay que tener en cuenta además que los eventuales modos de ocupación y explotación de la tierra anteriores a la instalación de los colonos no parecen haber influido en las formas creadas por ésta, hasta el punto de que se asienta sobre un vacío debido a la inexistencia de una red de hábitat y ocupación del suelo digna de ese nombre por parte de la población indigena capaz de articular el territorio en su conjunto y de explotarlo de manera sistemática, en un contexto caracterizado por la habitación en pequeños poblados fortificados matizados por influencias de Turdetania, más presentes en el área de Mérida ${ }^{55}$. Esa aparente radical ruptura entre los modelos pre-romanos y los nacidos del establecimiento de las colonias de Mérida, Norba o de núcleos como Trujillo, contrasta con el tránsito más gradual que se da en otras áreas citadas, como Cataluña, Valle del Ebro, o en el Bajo Guadalquir. En esos lugares podemos reconstruir un proceso de cambio que transformará los modelos de estructuración del espacio, no asi en Lusitania. Este hecho hace pensar en la existencia de un "vacío" al menos aparente que necesita explicación dado que no fueron áreas despobladas y que plantearon problemas graves de control a Roma. Es dificil adelantar una explicación cabal al fenómeno, pero creemos que una sugerencia de Brunt, que se refiere a la posible influencia del estado de guerra en la desarticulación del mundo indígena, con masacres, huidas de población, esclavitud, etc., que facilitarían la desposesión de los habitantes o que prepararían las condiciones idóneas para una instalación de colonos sobre amplios territorios casi abandonados, explicarían la situación de

${ }^{54}$ No estamos tampoco de acuerdo con la relación que se trata de establecer entre la evolución de la propiedad en la colonia con avatares económicos derivados de medidas como la prohibición de Domiciano sobre las viñas, y la disposición, permitiendo su cultivo. por Probo en el siglo III, aducida por BlázQuez, J. M., Estructura social y económica de Hispania durante la Anarquia Militar y el Bajo Imperio. Madrid 1964, pág. 13; Idem, Economia de la Hispania Romana, pág. 499 y por GARCia IGLESIAS, L., "Panorama económico Augusta Emerita...", p. 100, basándose en los postulados de Rostovtzeff, HSEIR. Madrid 1981, pág. 398-9.

${ }_{55}$ CerRillo, V. E., La vida rural romana en Extremadura, págs. 42-45. El panorama de estos asentamientos prerromanos es pobre, la base agraria rudimentaria, y la actividad ganadera bastante importante, aunque la existencia de la trashumancia, aducida por CERRILLO, E., ibidem, pág. 43 nos parece carente por completo de base. Para Trujillo tambièn constatan E. Cerrillo y Fernández Corrales, que en el patrón de ocupación del espacio en época romana, la estructura indigena interior, en castros fortificados no influye nada: véase, “Contribución de Estudio del asentamiento romano: Análisis espacial aplicado al Sur de Trujillo (en adelante: "Espacio y poblamiento romano al Sur de Trujillo"), Norba I, 1980, pág. 169. 
esa parte del país, castigado por las guerras desde Viriato, pasando por las luchas contra Sertorio, etc. El área de Mérida estaba muy probablemente por las circunstancias apuntadas en las mismas condiciones que Cartago, Corinto, o Augusta Praetoria en el Norte de Italia, lugares en los que en diversos momentos la ruptura provocada por Roma en su desarrollo histórico crea una situación nueva sin cohexión con la historia pasada. En esta tabla rasa que con el pasado se produce, nacen las colonias de César y Augusto ${ }^{56}$. En unas áreas la despoblación indigena sería un hecho, aunque en otras esa población se mantendría pasando a ser contributi de la nueva colonia.

Es bastante problemático reconstruir el proceso de transformación del espacio en el territorio de Mérida porque es controvertida la evolución de la implantación rural y la forma de explotación del territorio de Mérida $y$ el de las tierras vecinas a partir de la fundación de la colonia y el asentamiento de los colonos. Los investigadores que, como E. Cerrillo y J. M. Fernández Corrales prospectan el espacio extremeño desde hace 20 años, parecen pensar en una escasa implantación rural en los primeros tiempos, porque las parcelas concedidas no eran suficientemente productivas ${ }^{57}$ y la vida urbana produciría más atracción ${ }^{58}$. El asentamiento denso y la ocupación organizada del espacio sería realizada tardiamente, más allá del siglo $\mathrm{II}$, y como reflejo del proceso de ruralización del Bajo Imperio ${ }^{59}$. L. García Iglesias considera que ya desde la segunda mitad del siglo । d. C. tendría lugar la aparición de latifundios, muestra de que las disposiciones que prohibían la enajenación de los lotes recibidos por los primeros colonos perderían eficacia y permitirian que se acumulasen progresivamente las tierras ${ }^{60}$. Ante este panorama la situación puede resumirse expresando la existencia de una red de ocupación del territorio traducida en asentamientos numerosos, villae, poco conocidas por falta de excavaciones, pero que muestran un evidente desarrollo en el siglo IV, sin que nos sea posible establecer con certeza una continuidad entre estos establecimientos y sus hipotéticos precedentes desde los tiempos de la fundación de la colonia, y, a través de ellos, relacionar

56 Véase Brunt, Italian Manpower, pág. 246, menciona explicitamente a Lusitania entre las áreas en las que se puede haber dado la desaparición práctica de la población anterior en el territorio de las colonias romanas alli fundadas.

57 Cerrillo, E., y Fernández Corrales, J. M., "Contribución al estudio del asentamiento romano en Extremadura: Análisis espacial aplicado al S. de Trujillo», Norba, I, 1980, pág. 170 .

58 BALIL, A., "Riqueza y sociedad en la España romana", Hispania, 25, 1965, pág. 354.

59 Cerrillo, E., Fernández J. M., ibidem, pág. 172.

60 Garcia Iglesias, L., “Panorama económico Augusta Emerita...”, pág. 106 
formas de propiedad, formas de asentamiento y formas de articulación del espacio rural. Por ello, trabajos como los que E. Cerrillo o Fernández Corrales cobran especial valor como guías y marcos que permitirán perfilar con precisión los objetivos de la exploración arqueológica, que así puede responder a muchas de las cuestiones que sus modelos teóricos suscitan; en especial el momento y el ritmo de las transformaciones que permiten que nazca la red de ocupación del espacio que presentan para el territorio de Trujillo, o para el de Norba, a los que podemos añadir el caso de Medellin ${ }^{61}$ que, traduce la existencia de una jerarquización de núcleos en cuya cúspide estaría la capital provincial, pero que permitiria también un papel activo de centros intermedios como el citado últimamente, que es otra fundación colonial, o como el primero que parece haber sido dependiente de Emerita, y contribuyen a solidificar una estructura de organización del espacio cuya base son las villae que se distribuyen según unos criterios de distancia del centro urbano bien determinados y que si bien presentan ciertas diferencias según los casos, no dejan de responder a una lógica espacial en la que también juega su papel la estructura de las comunicaciones. El resultado es una implantación de establecimientos rurales en anillos concéntricos en los que la distancia del núcleo implica una mayor o menor densidad de villae ${ }^{62}$. Pero los esquemas de distribución de establecimientos que presentan estudios como el citado no bastan para conocer otras variables fundamentales, como la relación entre esos establecimientos y las formas de propiedad, o su tamaño, y el lugar de la población campesina en este

${ }^{61}$ El estudio de AMO Y DE LA HERA, M. del, muestra la importancia de una implantación rural que se adivina densa en los alrededores de Medellín: "Estudio preliminar sobre la romanización en el término de Medellín (Badajoz). La necrópolis del Pradillo y otras villas romanas", Noticiario Arqueológico Hispano, 2, Arqueología, 1973, pág. 51-130.

${ }_{62}$ En Trujillo el modelo de ocupación que resulta del análisis de las condiciones naturales y de los yacimientos conocidos efectivamente, se caracteriza por una intensificación de los yacimientos a partir de un radio de $5 \mathrm{~km}$ alrededor del núcleo, y, sobre todo, entre 10 y $20 \mathrm{~km}$ del núcleo, siendo el primer anillo, el de 0 a $5 \mathrm{~km}$, un completo vacio que los autores explican por la concurrencia de factores de tipo natural desfavorables, y de factores humanos derivados de la fuerza de atracción del núcleo como lugar de habitación. Véase: Cerrillo, E. y Fernandez Corrales, J. M., “Espacio y poblamiento romano al S. de TrujiIlo...". En el valle del Salor, en territorio de Norba, el limite de la primera orla se establece en los $10 \mathrm{~km}$ y, como en el caso anterior el área más próxima a la ciudad está vacía, pero entre los 5 y los $10 \mathrm{~km}$ empiezan a aparecer establecimientos, sin embargo, en las orlas siguientes, entre 10 y $20 \mathrm{~km}$ y entre 20 y 30 , al contrario que en el caso anterior la proporción de asentamientos es idéntica, hecho que explica el autor por la homogénea calidad de la tierra en esas áreas, las fáciles comunicaciones y la posible confluencia de la atracción de Emérita con la de Norba. Véase Fernandez Corrales, J. M., “El asentamiento rural romano en torno a los cursos alto y medio del Salor: su marco geográfico y su distribución", Norba IV, 1983, pág. 220-1. 
modelo. Sin embargo son posibles comparaciones con otros territorios de ciudades en los que se aprecian unas idénticas tendencias en la organización del espacio rural a partir de sus núcleos, como en Uxama, donde una serie de villae conocidas siguen respecto de la ciudad unas distancias determinadas conformando anillos concéntricos ${ }^{63}$. En otros casos, como en los territorios de Baetulo e lluro si bien no está establecida una organización en circulos concéntricos, hay una evidente concentración de las villae explicable por el papel central que esos núcleos urbanos juegan en la vertebración de un territorio pequeño pero fértil, siendo las tierras bajas las que más densa implantación presentan ${ }^{64}$.

\section{RELACIÓN ENTRE EVOLUCIÓN ECONÓMICA Y PROSPERIDAD DE LAS VILLAE EN LA PENINSSULA HASTA EL SIGLO III}

El objetivo que nos proponemos, en este apartado, es tratar de descubrir relaciones entre el proceso de desarrollo de las villae y la coyuntura económica, buscando los posibles paralelismos entre los movimientos que, a escala provincial o mediterránea se producen en la actividad económica. Se tratará de ver si las oscilaciones en la vida de algunas villae de Italia Central, y su decadencia ya desde fines del siglo I d. C. tienen su equivalente en la Península, y si se puede relacionar implantación de villae en la Península con determinadas corrientes comerciales.

En el contexto que acabamos de exponer, debemos analizar el problema de la continuidad de la implantación de las villae y de los modelos de ocupación del espacio. El aspecto que centrará nuestra atención será el modelo de ocupación del territorio vigente a lo largo del Alto Imperio; nos interesa ver si las tendencias que rigen el proceso de expansión de las villae pueden ser relacionadas con coyunturas económicas determinadas o si podemos hablar de un proceso con autonomía propia que no dependa de esas circunstancias coyunturales.

Responder a la cuestión que acabamos de formular implicaría, además de un conocimiento de las tendencias determinantes de la economía romana, y un conocimiento mejor del que disponemos sobre la evolución de los establecimientos rurales de la península, que pudiese detectar en

${ }^{63}$ Véase, Garcia Merino, C., "La ciudad de Uxama. Il». BSAA XXXVII, 1971, págs. 85 Ss

${ }^{64}$ Prevosti, M., op. cit., pág. 278. 
ciertas áreas concretas o en ciertos momentos oscilaciones traducibles en fases de decadencia o transformaciones de esos establecimientos. Al no permitir el estado de investigación de las villae peninsulares obtener conclusiones determinantes sobre ese punto, debemos retener ante todo la impresión que el conocimiento que tenemos nos da de expansión constante y progresiva que acaba cubriendo todo el país. Por ello debemos relacionar expansión de la romanización con la del modelo urbano, por una parte y el de la villa en el ámbito rural, por otra, que viven en una simbiosis motivada por la dependencia mutua de tipo económico y de tipo social ${ }^{65}$. En este contexto de expansión continua podemos intentar descubrir la influencia de ciertos factores que pueden dar en algunas regiones un carácter especial a su paisaje, pero especialmente revelador es trazar la posible influencia que entre determinados rasgos de la evolución económica de Italia y la de la península ibérica se podría dar, como consecuencia de los procesos de expansión de cierto tipo de producciones en respuesta a demandas como la que Roma y las fronteras del Imperio realizaban.

Existen unas evidentes corrientes de circulación de bienes que tienen como núcleo organizador preferente la ciudad de Roma, porque al ser capital del Imperio y, además, una gran ciudad, de dimensiones que sobrepasaban a las de cualquier otra de las escasas grandes ciudades del Mediterráneo, confluian en ella una serie de corrientes de importación que reunían un abastecimiento oficial, un abastecimiento privado y un abastecimiento que alimentaba el mercado. Italia y las provincias contribuian a esas necesidades de modos diversos, pero la cuestión el papel de ambas no se explica en términos de competencia, sino de complementariedad. Atribuir el incremento de las exportaciones desde las provincias hacia Roma a la decadencia de la agricultura italiana, está fuera de nuestros propósitos, una vez que, no ha sido correctamente enunciada por sus defensores, que tienden a confundir dos problemas: el del abastecimiento de Roma y el de la vitalidad de la agricultura de Italia. Por el contrario, cada vez parece más evidente que la correlación es a todas luces falsa ${ }^{66}$.

${ }^{65}$ Recordamos el papel de la aristocracia urbana como impulsora de la expansión de la villa, que se da tanto en ltalia como en las provincias, y los lazos que en el plano económico la existencia de la ciudad unen a ésta con el campo por medio de estas posesiones rurales en manos de sus propias oligarquias gobernantes, que asi incrementan su riqueza abasteciendo a la ciudad, a la vez que su poder.

${ }^{66}$ Rostovzeff, Historia social y Económica del Imperio Romano. vol. I, págs. 390-407, Sirago, La ltalia Agraria sotto Traiano. Lovaina, 1958, págs. 250-74; en favor de la decadencia agraria de ltalia, M. ${ }^{a}$ L. $^{a}$ Sánchez León también relaciona la situación económica 
Es evidente que podemos establecer una casuística que dará lugar a circunstancias diversas en las distintas regiones de la Península. En la configuración del paisaje rural en la región costera catalana, parece evidente que tiene un lugar muy destacado la expansión de la vid, cuyo producto llegó a Roma desde la época de Augusto en cantidades crecientes, tratándose, según muestra Tchernia de un comercio de abastecimiento de vino común para el consumo de la ciudad, complementando el papel de otras regiones provinciales, como la vecina Galia Narbonense $y$, por supuesto Italia, donde esta explotación se mantiene e, incluso intensifica. Un patrón de economía agraria como éste, determinó la configuración del paisaje agrario, contribuyendo a que se consolidase un modelo caracterizado por la vigencia de la mediana o pequeña explotación, que era la más adecuada para un cultivo productivo de esta planta, tal como recomiendan los agrónomos. De este modo, la densidad de explotaciones de la costa catalana estaría en relación, no sólo con unas modalidades de organización de la propiedad, sino con una base económica orientada hacia una especialización en el vino que alcanzaría preponderancia creciente a partir de fines de la República, y que encontraría en unas óptimas condiciones de clima, tierra, y suelo, por una parte, y en una estructura de la propiedad y una vinculación con Italia sin obstáculos, por otra, las más favorables circunstancias para que fuese el soporte del desarrollo económico. No es casual que un área como la de Baetulo e lluro cuya prospección hace conocer una red tan densa de establecimientos rurales coincida con la región de Laietania, de la que en Roma se consumían vinos de la más baja calidad. Las condiciones y la proximidad a Italia permitían una organización de la economía agraria en la que la viña jugaria un papel protagonista como cultivo comercial ${ }^{67}$. En la región de Tarraco y en la de Sagunto los mismos condicionantes favorables y su situación costera, como en el caso anterior crearían condiciones comparables que se traducirian en el establecimiento de explotaciones orientadas a una producción de excedentes de vino.

La producción del vino en la Tarraconense debe haber continuado no sólo a lo largo de los siglo I y 11 , período para el que las noticias de escritores clásicos, como Plinio el Viejo, Silio Itálico, Marcial, Juvenal y

floreciente de la agricultura bética con una crisis de la agricultura italiana desde el siglo 1; Véase, Economia de la Hispania Meridional de los Antoninos, págs. 181-2. Tchernia, muestra la falsedad de esta creencia en un aspecto fundamental como es la producción de vino; GaRnSEY \& SALLER, The Roman Empire Economy. Society and Culture. Londres 1987, págs. 58-9, $72-3$ limitan el alcance de esa decadencia y la niegan en aspectos agrarios relacionados con la agricultura especializada.

${ }_{67}$ Véase TCHERNIA, Le vin d'ltalie, págs. 174-5, 179. 
Frontón nos dan referencias ilustrativas citando los vinos malos de Laietania y Sagunto, y los de más calidad de Tarraco y Lauro ${ }^{68}$, y el estudio de las ánforas del tipo Dressel 2-4, que hasta el reinado de Adriano llegan a Ostia y Roma ${ }^{69}$, sino que también más allá del siglo III, y después del 260 , momento más dramático de la crisis, continuaria esa producción. Por arriesgada que pueda resultar la afirmación es preciso suponer que una continuidad como la que se manifiesta en zonas como lluro y Baetulo ${ }^{70}$, aunque alterne con signos de ruptura en otras áreas como la de Liria ${ }^{71}$, otra zona productora de vinos o más al norte, en las cercanias de Tossa de Mar, implica una pervivencia de las estructuras de explotación, de propiedad y de cultivos que dificilmente se podría haber roto bruscamente. Después del siglo III tenemos ejemplos suficientemente indicativos de la continuidad de la explotación de la vid en villae destruidas en ese siglo que se restauran en el iv, como la de Pacs, que aunque sea más pobre continúa con esa dedicación ${ }^{72}$. Creemos muy adecuada la observación que $A$. Tchernia apunta sobre la discordancia de los datos proporcionados por el estudio de las ánforas y el de la arqueología de los establecimientos rurales, que a primera vista producen resultados contradictorios, como referencia que nos ayude a evitar conclusiones precipitadas sobre las tendencias que en el plano económico determinaron la implantación en el espacio rural de las villae y, por extensión, las características del paisaje agrario romanizado ${ }^{73}$. Sus observaciones, que también aluden a los problemas de la región tarraconense

${ }^{68}$ Sobre el vino de Tarragona; PLINIO XIV, 71; SILIO ITÁLICO, III, 369 y XV, 178; MARCIAL XIII, 118. Sobre el de Lauro; PLINIO, ibidem. Sobre el vino de Sagunto: JuvENAL, V, 29; Fronton, Ep. de elocuentia, I, 1. Sobre el de Laietania: MARCIAL, I, 26, 9-10; VII, 53; PLINIO, ibidem.

${ }^{69}$ Conviene recordar los estudios de R. Pascual, y R. Callender. Véase, TCherniA, A., Le vin d'ttalie, pág. 271-2.

70 Gorges lo adelantaba y $\mathrm{M}$. Prevosti lo confirma en sus estudios de lluro y Baeutlo, aunque el momento de mayor prosperidad corresponda al siglo ॥ d. C.

71 Véase TARRADELL, "Población y propiedad rural en el este peninsular durante el Bajo Imperio", Actas del III congreso español de Estudios Clásicos, II. Madrid 1968.

${ }^{72}$ Cfr. BaLll, A., "La villa romana de Pacs (Penedés, Barcelona)" BSAA, LIII, 1987, pág. 181-9. Muestra que la villa de Pacs sufre un cambio de vida a partir de cierto momento; la existencia de dolia para almacenar empotrados en pavimento musivo y que, como en otros lugares hubo un cambio de nivel de vida debido a un cambio de propietarios, menos exigentes en lujos que los anteriores, o una adaptación a tiempos difíciles, con un cambio de destino a fines utilitarios de dependencias nobles.

${ }^{73}$ TCHERnIA, Le vin d'italie, pág. 264- 272. Insiste en las dificultades que en la propia Italia plantea la interpretación de las ánforas como indicador de importaciones, y las villae que tienen una historia muy diversa y cuyos periodos de esplendor y abandono en épocas tempranas como sucede en casos de Etruria y el Lacio crea discusiones que se tratan de incardinar en concepciones sobre la decadencia de la economia agraria italiana y sobre la crisis del tipo de explotación esclavista. 
han de servirnos para comprender mejor la evolución de la implantación rural romana, en la que debemos ver una combinación entre los efectos de los condicionantes naturales y los humanos; hemos de aceptar además que si bien los impulsos que haga sentir el mercado de Roma o las solicitaciones del fisco contribuyen a configurar ciertos rasgos de ese paisaje agrario, no podemos esperar que se sientan de la misma manera que en los tiempos actuales en regiones que basan su economía agraria en productos de exportación. Por el contrario, en la península, incluso en las áreas citadas de la Tarraconense, o la Bética, creemos oportuno insistir en la fuerza de la autosuficiencia en la conformación de toda explotación agraria; existe un equilibrio que se mantiene entre los diversos cultivos con la única variación de la insistencia en alguno, del que interese obtener excedentes exportables, como previsiblemente ocurría con la vid en la costa catalana y valenciana, y con el aceite en el valle del Guadalquivir. Creemos que las variaciones de la demanda en mercados lejanos no tenian fuerza suficiente como para alterar las tendencias de consumo a largo plazo y para trastocar completamente la estructura de la producción de una región ${ }^{74}$. El papel de la ciudad de Roma es especial, evidentemente, pero el efecto transformador de su magnitud demográfica se sintió en ciertas regiones de Italia próximas, mientras que en el resto del imperio el papel de la recaudación de la annona o el flujo de bienes por medio del comercio o del abastecimiento interno, no implicaba una radical reestructuración del espacio y de la economía rural para transformar los patrones anteriores en el equivalente a economias de plantación, aunque no se puede subestimar la fuerza que la orientación especializada en ciertas regiones favorecidas, como la Bética o África del Norte, confería a las producciones que alimentaban la annona militaro o la de Roma y, por ende, también un comercio.

Nuestro propósito consiste, por todo ello, en separar la evolución de la expansión de las villae en la península de la hipotética demanda de productos hacia mercados exteriores. Si la villa supone un cambio radical en la articulación del espacio y en la economia agraria de muchas áreas que anteriormente tienen unas estructuras primitivas y una debilidad evidente desde el punto de vista de la producción, ese progreso sólo en

74 La demostración más evidente es la continuidad de las villae que en Etruria producían el vino que desde la segunda mitad del siglo II a. C. se exportó en grandes cantidades a la Galia independiente. El final de ese comercio con la conquista no produjo una crisis del viñedo tirrénico por dos razones: la producción cuantitativamente elevada que se exportó a la Galia era una parte pequeña de la producción de estas villae y la proximidad de Roma era un factor más importante que ese mercado lejano. Veáse, TCHERNIA: Le vin d'ltalie, pág. 74 ss., 302 ss. 
limitada medida se orienta a necesidades ajenas a la simple autosuficiencia; tal como el progreso de la urbanización o de la situación en áreas con fácil acceso al exterior, siendo, a la vez, un signo de la integración en la élite romana de familias e individuos que, al hacerse senadores o equites, amplían el ámbito de su autosuficiencia, promoviendo una circulación hacia Roma de los productos de sus dominios peninsulares, con la posiblidad de incrementar sus ingresos vendiendo excedentes en el marcado; pero éste no es, sin embargo, el motivo de la implantación del modelo de la villa. Al igual que el modelo urbano, la villa representa en el campo un patrón que goza del prestigio de lo romano, y es vehículo de implantación de formas de vida romanizadas transmitidas primero por los conquistadores que se instalan y que son asumidas por los elementos dirigentes de las comunidades indígenes, que asi mantienen una red de dependencias que, como en la Galia, permite que las formas en las que basaban su influencia y poder en la época prerromana, una vez transformadas les permitan mantener su posición privilegiada en un marco de romanización; al mismo tiempo, en otros lugares con estructuras menos evolucionadas, permite que los liderazgos frágiles de la etapa anterior a la conquista se conviertan en lazos más sólidos al compás de la descomposición de los cuadros organizativos anteriores. La propiedad privada, primada por los romanos, permite que ciertas familias traduzcan un liderazgo, que ejercían en una formación social poco diferenciada, en una sólida posición apoyada en la extensión de grandes dominios y en la dependencia económica de los antiguos miembros de su unidad ${ }^{75}$.

Por todo lo anterior si hemos de interpretar la expansión de las villae no sólo en el Alto Imperio, sino también en el siglo IV, época a la que pertenecen los niveles conservados de la mayoría de las villae y que asiste a su mayor esplendor, hemos de alejarnos de explicaciones basadas exclusivamente en situaciones coyunturales de demanda comercial y centrar la explicación de sus causas en la evolución interna de las sociedades.

75 Por esta vía debemos entender la romanización de áreas como la de los vetones: SaLINAS, M., La organización tribal de los vetones. Salamanca 1982, o entre los astures y galaicos pueblos entre los que la romanización al suponer alterar progresivamente su base económica y sus instituciones sociales, con el dislocamiento de sus sociedades, a través de sus grietas surge una diferenciación de los individuos que se traduciria por fuerza en la aparición de ricos que edifican villae en las tierras que recibieron o que se apropiaron con el estímulo de la administración romana. Véase LOMAS SALMONTE, F. J., Asturias prerromana y Alto Imperial. Sevilla 1975. 